\title{
Pasquill's Influence: On the Evaporation from Various Liquids into the Atmosphere
}

\author{
C. H. Huang \\ Date Published \\ September 1995
}

To Be Presented at

Ninth Joint Conference on the Applications of Air Pollution Meteorology with the Air and Waste Management Association American Meteorological Society Attanta, Georgia January 28 - February 2, 1996

Prepared for the U.S. Department of Energy Assistant Secretary for Environmental Management

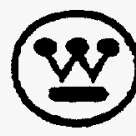

Managament and Operations Contractor for the

U.S. Depertment of Energy under Contract DE-ACD8-87RL 10930

Copright Liomes BV scceptence of this artida the pubither and/or recipient acknowledges the

U.S. Government's riptit to rotain a nonexchuive, royditytres Ficense in and to any copyright covering this paper. 
LEGAL DISCLAIMER

This report was prepared as an accourit of work sponsored by an agency of the United States Government. Neither the United States Government nor any agency thereof, nor any of their employees, nor any of their contractors, subcontractors or their empioyees, makes any warranty, express or implied, or assumes any legal liability or responsibility for the accuracy, completeness, or any third party's use or the resuits of such use of any information, apperatus, product, or process disclosed, or represents that its use would not infringe privately owned rights. Reference herein to any specific commercial product, process, or service by trade neme, trademerk, manufacturer, or otherwise, does not necessarily constitute or imply its endorsement, recommendation, or favoring by the United States Government or any agency thereof or its contractors or subcontractors. The views and opinions of authors expressed herein do not necessarily state or reflect those of the United States Government or any agency thereof.

This report has been reproduced from the best available copy.

Prinsed in the Unired States of Amence

DISCLM-2.CHP (1-91) 


\title{
PASQUILL'S INFLUENCE: ON THE EVAPORATION FROM VARIOUS LIQUIDS INTO THE ATMOSPHERE
}

\author{
C. H. Huang \\ Westinghouse Hanford Company \\ P.O. Box 1970 \\ Richland, Washington 99352
}

\section{INTRODUCTION}

Pasquill's development of an evaporation model as well as his experimental work on the subject are important in view of the recent emphasis on toxic chemical releases to the enviranment. Pasquill's contributions to the ficld of "atmospheric diffusion" are enormous and well-known. The Pasquill stability classification enables us to apply the Gaussian diffusion model in our daily life. The Gaussian diffusion model has been widely and rourinely applied in industry for the estimate of the ais concentration and to manage the radioactive and hazardous wastes in recent years. Equally important but no less than his contribution to the Gaussian diffusion model is Pasquill's intluence on the subject of evaporation from various liquid surfaces into the atmosphere.

An evaporation model taking into account the vertical variations of the mean wind speed and the eddy exchange coefficient was first introduced by Sutton (1934). The Sutton model made it possible to estimate toxic chemical release from a smooth liquid surface to the environment. However, in the Sutton model, the process of vapor transfer is based on the momentum exchange involving a parameter of the air viscosity. Subsequently, Pasquill (1943) modified Sutton's evaporation theory by introducing another new parameter, the molecular diffusivity. This replaced the viscosity in the Sutton model, an important missing parameter. The Sutton-Pasquill evaporation model has found wide applications in industry for half a century. However, out of these two parameters, a non-dimensional parameter can be formed; it can be used to modify the Pasquill evaporation model. Experimental data in the laboratories and the fieids indicate that the rate of evaporation from a liquid surface is dependent on a Schmidt number. Thus, in this study, we will consider the modification of the Sutton-Pasquill model and provide some theorecical justifications.

\section{SUTTON'S EVAPORATION MODEL}

A theoretical treatment of the removal of water vapor from a free-liquid surface into the atmosphere was first introduced by Sutton (1934). Sutton in his theoretical treatment of evaporation considered the analogy between the vapor transfer and momentum transfer. The basic equation
Sutton considered is a two-dimensional diffusion equation which may be written as:

$$
u(z) \cdot \frac{\partial x}{\partial x}=\frac{\partial}{\partial z}\left(K_{z} \frac{\partial x}{\partial z}\right)
$$

The evaporation problem considered by Sutton is a strip of a freo-liquid surface with an infinite extent in cross wind direction and finite dimension in down wind direction. Where $u(z)$ is the horizontal mean wind speed, $\chi$ the concentration, $K_{z}$ the eddy diffusivity, and $x$ and $z$ the coordinates in the down wind and the vertical directions, respectively. The wet surface area is defined by $0<x<$ $x_{0}$ for $z=0$, while for $x>0$ or $x<0$, the ground is assumed to be dry as shown in Fig. 1.

With the wind profile and the eddy diffusivity spocified, the solution for Eq.(1) for the rate of evaporation is obtained as

$$
\begin{aligned}
& E_{T}\left(u, x_{0}\right)=A u^{(2-\pi)((2 m)} x_{0}^{2 /(2+n)} \text { or } \\
& E_{T}\left(u, x_{0}\right)=A u^{0.78} x_{0}^{0.89} \text { for } n 0.25
\end{aligned}
$$

where $\mathrm{A}=\mathrm{K} \chi_{\mathrm{a}}$

Thus, the total rate of evaporation per unit width in the cross wind direction over a fetch $x_{0}$ from a smooth surface can be calculated from Eq.(2) or Eq.(3). For pracrical applications, the values of $K$ for various values of the atmospheric intensity index, $n$, were calculated by Pasquill (1943). The equation has often been used to estimate the release of hazardous materials into the atmosphere.

\section{PASQUILL'S EXPERIMENTAL WORK}

Various researchers considered the evaporation from a piane, liquid surface. However, insufficient attention has been paid to study the aerodynamic effects on the evaporation. Thus, Pasquill (1943) set out to conduct his experiments and to investigate the effects of the airflow over a liquid surface on the rate of evaporation. He examined the experimental results conducted in a wind tunnel in the light of the evaporation theory in turbulent flow developed by Sutton (1934). In recognizing the shortcoming of the 
Sutton's theory, i.e., the process of evaporation from a free-liquid surface is controlled by the viscosity of air rather than the molecular diffusivity; he subsequently proposed a generalized theory of evaporation based on the modification of Sutton's theory. However, Pasquill's generalized theory is mainly dependent on general physical considerations. To justify his theory, he carried out his experimental works in a wind tunnel and used bromobenzene as a liquid for the experiments. In his experiments, he showed that the original Sutton's theory overestimated the rate of evaporation which is also reproduced here as shown in Fig. 2 to facilitate the discussions. Sutton in his theory identified a parameter $\lambda$ with the kinematic viscosity of air $(\lambda=\nu)$. However, Pasquill suggested to replace the viscosity in the Sutton's theory by the molecular diffusivity.

\section{COMPARISON OF EXPERIMENTAL DATA WTTH THEORIES}

In this section, the experimental work conducted by Pasquill (1943) will be compared with the theories of evaporation (Sutton, 1934; and Pasquill, 1943).

To verify the evaporation model, Pasquill (1943) used bromobenzene to conduct a series of experiments. In general, his results are in good agreement with Sutton's theory, although Sutton's original theory somewhat overestimated the rate of evaporation. The comparison of the experimental data with Sutton's theory is shown in Fig. 2 (Pasquill, 1943). Fig. 2 shows that the data of the rate of evaporation obtained from wind tunnel experiments is normalized by the theory for the wind speed of $5 \mathrm{~m} / \mathrm{s}$. In Sutton's theory, Pasquill argued that the diffusion of momentum, heat, and mass is controlled primarily by the movements of eddies or masses of fluid. Eventually, these eddies mix with the air in its surroundings and must ultimately depend on the molecular motion. In the case of mass transfer, the molecular diffusion must play a dominant role for the turbulent transfer process of a substance. Therefore, Pasquill considered the molecular diffision an important parameter in controlling the process of mass transfer from a view point of the physical reasonings.

On the basis of the above analysis of the vapor exchange coefficient, Pasquill suggested to modify Sutton's theory and calculated the rate of evaporation from a free-liquid by replacing the parameter of the kinematic viscosity of air ( $\nu$ ) by the molecular diffusivity (D). In his paper, he further demonstrated the superiority of the so called generalized theory (Pasquill, 1943) over Sutton's theory of evaporation.

To date, his work in some ways has been widely adopted by many practitioners in the industries for the calculations of the toxic releases of volatile liquids into the environment.

\section{THEORETICAL JUSTIFICATION}

In the laboratories and the field experiments, it appears that the rate of evaporation from various liquids is dependent on a nondimensional parameter, the Schmidt number, with a power index of minus twothirds rule (see Mackay and Matsugu, 1973).

In the following, we will show that the rate of evaporation is dependent on the minus two-thirds power of a Schmidt number. As a demonstration of the concept, a set of basic equations will be used to obtain an analytical solution for the rate of evaporation. The basic equation considered is a two dimensional diffusion equation of the form as given in Eq.(1) in Section 2.

The solution for Eq.(1) can be obtained if we specify the boundary conditions and the wind profile: the boundary conditions, $x=0$ for $z>0, x=0$ and $x=x$. for $z=0, x>0$ and the wind profile $\mathbf{u}=u_{z} z / \nu$, where $u_{n}$ is the friction velocity. For the flow over a smooth surface, in the interfacial sublayer the diffusion process is presumably controlled by the molecular diffusivity and there exists a linear wind profile in this sublayer. With the boundary conditions and the wind profile specified, the solution of the diffusion equation, Eq.(1), can readily be obtained for the vapor density and the vertical flux of a diffusion substance. Thus, the mass transfer coefficient may be expressed as

$$
k_{n}=A_{0} S c^{-23}\left(2 u_{0}^{2} / x\right)^{2 / 3}
$$

where $A_{0}$ is a constant.

Since we are dealing with the diffusion process of an airflow over a smooth surface, we will also consider the drag force on such a flat surface in Eq. (4). The shearing stress, $\tau$, on a smooth, flat surface in the laboratory and the field may be expressed as

$$
u_{0}^{2}=t / p=a U^{2} \operatorname{Re}_{x}^{-1 / S} \text {. }
$$

Where $a$ is a constant which is equal to 0.029 according to the laboratory experiments, $U$ is an undisturbed mean wind speed, and $\operatorname{Re}_{x}$ a Reynolds number. 
Substituting Eq.(5) into Eq.(4), we have the transfer coefficient as

$$
\mathrm{k}_{\mathrm{m}}=\mathrm{A} \mathrm{Se}^{-2 / 3} \mathrm{Re}_{\mathrm{s}}^{-1 / 5}
$$

where $A$ is a constant. In practice, the constant $A$ should be determined from experimental data. Eq.(6) shows that the mass transfer coefficient follows the minus two-thirds power of the Schmidt number $(\nu / D)$; it also depends on the Reynolds number.

Then, the rate of evaporation over a fetch $x$ may be expressed as

$$
E_{T}=B \cdot e^{-23} \operatorname{Re}_{x}^{3 / s} \cdot x_{i} .
$$

The value of $B$ is a constant. The above results demonstrate that the rate of evaporation is dependent on the $-2 / 3$ of the Schmidt number. A somewhat different treatment of the diffusion process in the interfacial sublayer was given by Brutsaert (1975). He showed that for the flow over a smooth surface the interfacial transfer coefficient or the rate of local evaporation may be expressed as a Dalton's nuraber

$$
D a_{0}=E /\left(u_{0} .\left(x_{0}-x_{b}\right)\right)=C_{1} s c^{-2 \sqrt{3}}
$$

where $C_{3}$ is a dimensionless constant and $\chi_{k}$ is the vapor density at the top of the interfacial sublayer.

In Eq. (8), it further demonstrates that the rate of local evaporation of a substance from a fre liquid surface into the atmosphere is 2 function of the Schmidt number with a power index of minus twothirds.

Furthermore, the transfer coefficient according to Brutseart (1975) may also be expressed as

$$
k_{m}=u_{0}\left[13.6 S c^{-2 / 3}+(1 / \alpha)\left(C d^{-1 / 2}-13.5\right)\right]^{-1}
$$

where $\alpha_{0}$ is the inverse of the turbulent Schmidt number and $\mathrm{Cd}$ is the drag coefficient.

As a first approximation if we assume that the second term in Eq.(9) can be neglected and by virtue of Eq. (5), the friction velocity, un, in Eq. (9) can be eliminated.

Then, Eq. (9) becomes

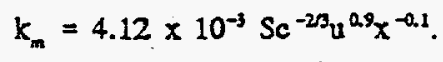

Thus, the rate of evaporation may be written as

$$
E_{T}=4.6 \times 10^{-3} \mathrm{Sc}^{-2 / 3} \times_{0} \mathrm{u}^{29} \times{ }^{0.9} .
$$

Again, Eq.(11) shows that the rate of evaporation is dependent on the Schmidt number with the power index of minus two-thirds.

\section{RESULTS}

Pasquill (1943) analyzed the experimental data obtained by the previous investigators. He compared his own experimental data and other data obtained by previous researchers with the generalized theory. The results are shown in Fig. 3. Fig. 3 shows that the rate of evaporation has been normalized by the theoretical rate of evaporation for wind speed, $u=3 \mathrm{~m} / \mathrm{s}$. The results show that the Pasquill's experimental data are in good agreement with the generalized theory.

But, as can be seen from Fig. 3, the experimental data obtained by other authors are not entirely in agreement with his theory. However, out of these two parameters ( $v$ and D), a new non-dimensional parameter, the Schmidt number can be formed. Furthermore, the experimental data obtained in the laboratory and the field, and the theories described above in the Section 5 all suggest that the rate of evaporation is dependent on a Schmidt number, $\mathrm{Sc}^{-23}$. Thus, the rate of evaporation may be expressed as

$$
E_{T}=c .5 e^{-2 s} x_{1} \cdot u^{0.7 \pi} x^{0.9}
$$

where $c$ is a constant to be determined from the experimental data. The value $c$ is found to be $5.5 \times 10^{-3}$ based on the analysis of Pasquill's experimental data. This equation is also plotted in Fig. 3 for various liquids, bromobenzene, toluene, and water. Eq.(12) shows much better agreement than the generalized theory with the experimental data for various liquids. The resuits indicate that the rate of evaporation depends on the $-2 / 3$ rule of a Schmidt number. It is evident that the rate of evaporation for various liquids also varies with the Schmidt number.

Similar to the plot as shown in Fig. 3, if we plot the product of the total rate of evaporation and the two-thirds rule of the Schmidt number, the results are shown in Fig. 4. Fig. 4 shows that the three curves generated from the proposed evaporation equation, Eq.(12), as displayed in Fig. 3 collapse into a single curve. And the proposed equation of the rate of evaporation for various liquids is in very good agreement with the experimental data.

The various formulas for the transfer coefficient (transfer velocity) and the equations used to predict the total rate of evaporation by various authors are given 
in Tables 2 and 3, respectively. The formulas with the numbers appeared in Tables 2 and 3 are in a metric system.

Table 2. Constants Associated with Various Transfer Coefficients $\left(k_{m}\right)$ by Various Authors.

\begin{tabular}{|c|c|c|c|c|}
\hline $\begin{array}{c}\text { Pasquill } \\
(1943)\end{array}$ & $\begin{array}{c}\text { MacKay } \\
(1973)\end{array}$ & Present & $\begin{array}{c}\text { TNO } \\
(1988)\end{array}$ & $\begin{array}{c}\text { ILLE } \\
(1979)\end{array}$ \\
\hline $2.95 \times 10^{-3}$ & $\begin{array}{c}4.8 \times 10^{-3} \\
. \mathrm{Sc}^{-2 / 3}\end{array}$ & $\begin{array}{c}4.9 \times 10^{-3} \\
. \mathrm{Sc}^{-23}\end{array}$ & $\begin{array}{c}2.0 \times \\
10^{-3}\end{array}$ & $\begin{array}{c}7.2 \times 10^{-3} \\
. \mathrm{Sc}^{-23}\end{array}$ \\
\hline $\begin{array}{c}2.95 \times 10^{-3} \\
\text { (bromoben- } \\
\text { zene) }\end{array}$ & $2.87 \times 10^{-3}$ & $2.95 \times 10^{-3}$ & $\begin{array}{c}2.0 \times \\
10^{-3}\end{array}$ & $4.3 \times 10^{-3}$ \\
\hline $\begin{array}{c}3.9 \times 10^{-3} \\
\text { (water) }\end{array}$ & $6.76 \times 10^{-3}$ & $6.9 \times 10^{-3}$ & $\begin{array}{c}2.0 \times \\
10^{-3}\end{array}$ & $1.02 \times 10^{-2}$ \\
\hline
\end{tabular}

Table 3. The Rates of Evaporation $\left(\mathrm{E}_{\mathrm{T}}\right)$ by Various Auchors.

\begin{tabular}{|c|c|c|c|c|}
\hline $\begin{array}{c}\text { Pasquill } \\
(1943)\end{array}$ & $\begin{array}{c}\text { MacRay } \\
(1973)\end{array}$ & Present & $\begin{array}{c}\text { TNO } \\
(1988)\end{array}$ & $\begin{array}{c}\text { ILLE } \\
(1979)\end{array}$ \\
\hline $3.32 \times 10^{-3}$ & $\begin{array}{c}5.4 \times 10^{-3} \\
. \mathrm{Sc}^{-2 / 3}\end{array}$ & $\begin{array}{c}5.5 \times 10^{-3} \\
. \mathrm{Sc}^{-23}\end{array}$ & $\begin{array}{c}2.25 \times \\
10^{-3}\end{array}$ & $\begin{array}{c}8.1 \times \\
10^{-3}\end{array}$ \\
\hline $\begin{array}{c}3.32 \times 10^{-3} \\
\text { (bromoben- } \\
\text { zene) }\end{array}$ & $3.22 \times 10^{-3}$ & $3.32 \times 10^{-3}$ & $\begin{array}{c}2.25 \times \\
10^{-3}\end{array}$ & $\begin{array}{c}4.84 \times \\
10^{-3}\end{array}$ \\
\hline $\begin{array}{c}4.38 \times 10^{-3} \\
\text { (water) }\end{array}$ & $7.60 \times 10^{-3}$ & $7.75 \times 10^{-3}$ & $\begin{array}{c}2.25 \times \\
10^{-3}\end{array}$ & $\begin{array}{c}1.14 \times \\
10^{-2}\end{array}$ \\
\hline
\end{tabular}

As can be seen from Tables 2 and 3 , the constants associated with the transfer coefficient and the rate of evaporation of bromobenzene or water vapor predicted by the present author are remarkably close to those predicted by MacKay and Matsugu (1973). The rates of water vapor predicted by Pasquill (1943) are lower than those predicted by MacKay and Matsugu (1973) and the present author by 1.7 and higher than that of TNO (1988) by 1.9 times.

The constants associated with the transfer coefficient in Eq.(10) and the rate of evaporation in Eq.(11) derived by the present author are quite close to those values obtained by MacKay and Matsugu (1973) and the present author (see Tables 2 and 3).

Similarly, for a circular area of radius $r$, the rate of evaporation from various liquid surfaces into the atmosphere may be written as

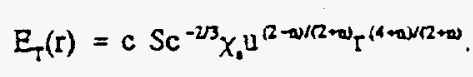

In practical applications, we may take $\mathrm{n}=0.25$, then, Eq. (13) becomes

$$
E_{T}(r)=c S c^{-23} x_{4} 4^{0.7 t_{T}} t^{1.9}
$$

where $c=1.64 \times 10^{-2}$.

\section{CONCLUSION}

Pasquill's equation for predicting the rate of evaporation for bromobenzene is close to the equation developed by MacKay and Matsugu (1973) and the present author. Pasquill's experimental data has been utilized to develop an equation of evaporation for the estimate of the rate of evaporation for the airflow over a free-liquid surface in the atmospheric boundary layer. The modified evaporation equation is based on the theoretical treatment of the evaporation process for air flow over a fetch. The predicted equation of evaporation by the present author is remarkably close to that of Mackay and Matsugu (1973). However, the rate of water vapor predicted by various authors is different. It appears that the evaporation equation including a mimus two-thirds of a Schmidt mumber is in much better agreement with a wide range of experimental data. Thus, additional experimental works in the laboratory or the field are needed to verify the rate of evaporation for various liquids under a much better controlled condition, in particular for the rate of evaporation for water vapor.

In addition, the theoretical justifications have been provided for the expression of the rate of evaporation over a fetch which includes a $-2 / 3$ Schmidt mumber in the formula. The rule of $-2 / 3$ Schmidt number in the evaporation formulation has also been confirmed by the observations obtained in the laboratories and the fields.

Pasquill's experimental work on the evaporation of various liquids still remains one of the important, viable sources that may be used to justify semiempirical or the theoretical work. It is a new challenge to continue Pasquin's effort in the estimate of the rate of evaporation from various liquid surfaces into the atmosphere, especially, to conduct the experiments under a much more controlled condition. It is up to us to canry out the torch of experimental or theoretical work left behind to us by Pasquill - a man of great contributions to the fields of rurbulence and diffusion and evaporation. 


\section{REFERENCES}

Brutsaert, W., 1975: A Theory for Local Evaporation (or Heat Transfer) from Rough and Smooch Surfaces at Ground Level., Warer Resour. Res. $11,543-550$.

Mle, G., and C. Springer, 1979: The Evaporation and Dispersion of Bydrazine Propellants from Ground Spills., CEEDO-TR-78-30, Air Force Engineering and Service Laboratory, AFESC. Tyndail, AFB, Florida, July, 1979.

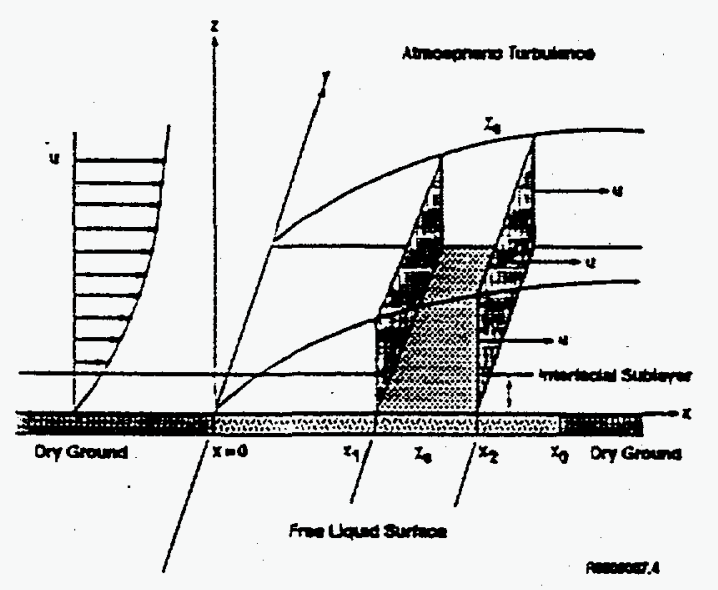

Figure 1. Evaporation from a Liquid Surface into the Atmosphere.

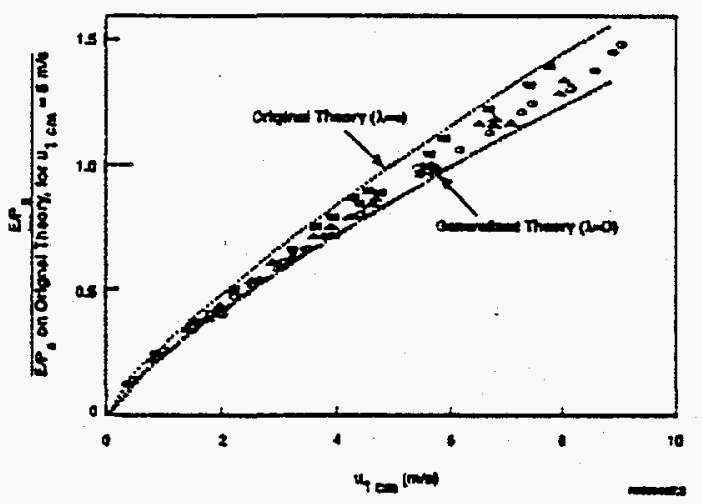

Figure 2. Comparison of Experimental and Theorerical Values for the Rate of Evaporation of Bromobenzene into a Turbuient Air Stream.
Mackay, D., and R. S. Matsugu, 1973: Evaporation Rate of Hydrocarbon Spills on Water and Land., Can. J. Chem. Eng., 5, 434.

TNO, 1988: Methods for the Calculation of Physical Effects., The Netheriands.

Pasquill, F., 1943: Evaporation from a Plan. FreeLiquid Surrace into a Turbulent Air Stream., Proc. Roy. Soc. A., 75-94.

Sutton, O. G., 1934: Wind Structure and Evaporation in a Turbulent Atmosphere., Proc. Roy. Soc. A, $146,701-722$.

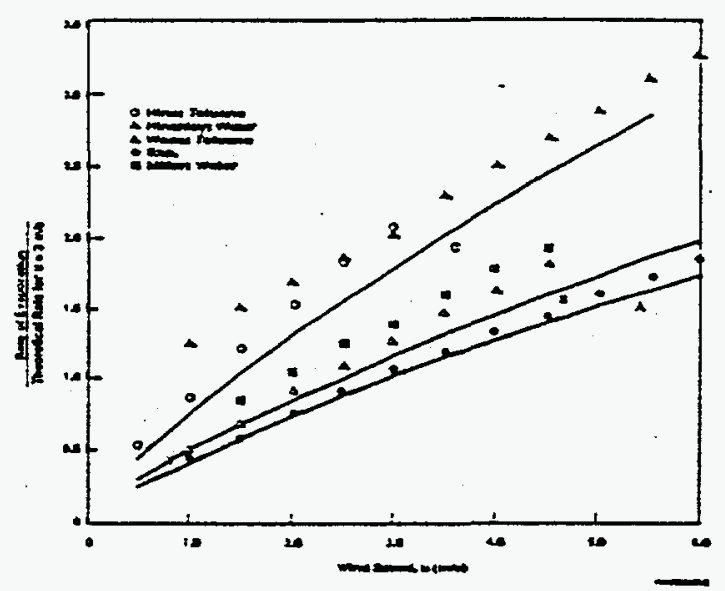

Figure 3. Rate of Evaporation into a Turbulent Air Stream: Comparison of Experimental and Theoretical Values. Theory: Curves A Bromobenzene,

$B$ Toluene, and $C$ Water.

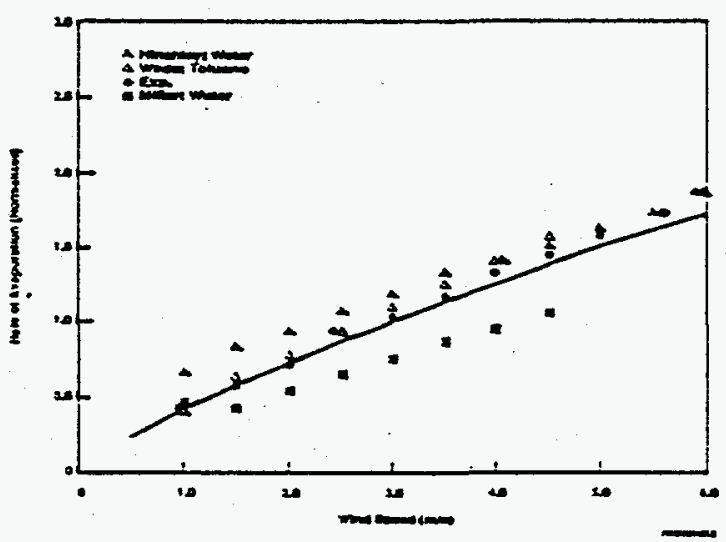

Figure 4. Comparison of the Theory with the Experimental Data. 